\title{
Regeneration of initial properties after fatigue damage in aluminium alloys
}

\author{
A. May, M. A. Belouchrani \& A. Britah \\ Materials Engineering Laboratory, EMP, Algeria
}

\begin{abstract}
In the present work, the effects of heat treatments on the evolution of oligocyclic fatigue damage on two types of aluminium alloys were studied. The two alloys are largely used in the aircraft industry because of their good mechanical characteristics and their lightness. The main factor influencing damage of these two types of alloys is decohesion of interfaces in $\mathrm{Al}-\mathrm{Si}, \mathrm{Al}-\mathrm{Cu}$ and $\mathrm{Al}-\mathrm{Mg}$ particles resulting from the stress concentration in these interfaces. Our work is to repair this decohesion by the use of specific heat treatments. The monitoring of the damage evolution is done by using the variation of electrical resistivity resulting from the microstructure transformations; this change of the microstructure is due to the variation of different parameters of annealing heat treatment. This method allowed us to find the best parameters of the heat treatments to use during repair. Those parameters are: temperature, maintaining time and speed of cooling. The idea of using heat treatments is based on the role of those heat treatments on the microstructure of material, on its behaviour before and after the first stage of fatigue damage. From this viewpoint, we had to make the microcavities created during the fatigue damage decrease; it will be only a contribution to the regeneration of the initial properties before this damage. The results obtained showed that the regeneration of the initial properties of the material after fatigue damage is possible with appropriate heat treatments and optimal treatment exists if a certain threshold of damage is not reached. Finally, this process can be envisaged to increase the fatigue life of components when these are submitted to fatigue loading.
\end{abstract}

Keywords: fatigue damage, heat treatment, aluminium alloys, electrical resistivity and microstructure. 


\section{Introduction}

Fatigue of metals is usually identified as an irreversible process. However, methods of regeneration exist (Lü et al. [1]). On a purely comparative basis, tired people or animals can refresh themselves by having a meal and a rest. According to this idea, it is supposed that, if a metal specimen has certain cycles of mechanical loading, some microcavities will occur in its microstructure and encourage this specimen to be in a state of non-equilibrium, i.e., a condition of damage by fatigue. If the energy lost during this fatigue is introduced into the

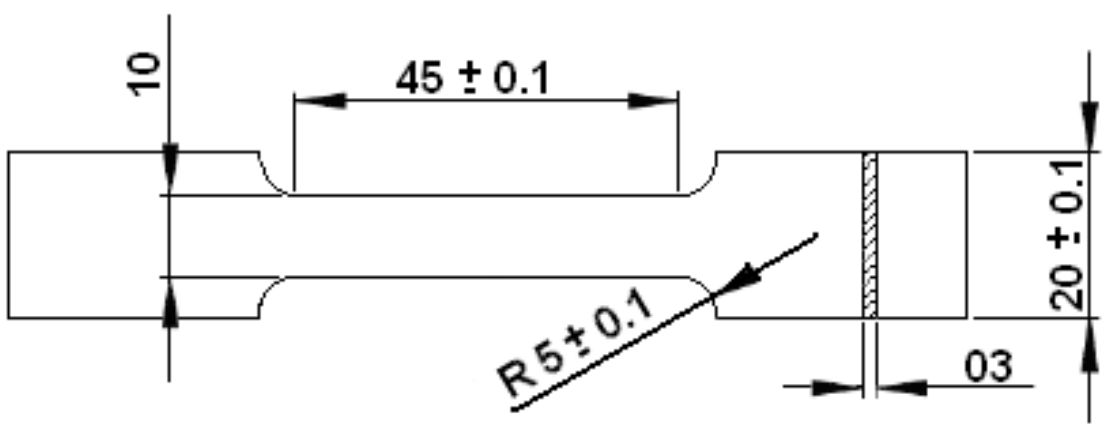

Figure 1: $\quad$ Specimen of tensile and fatigue damage test.

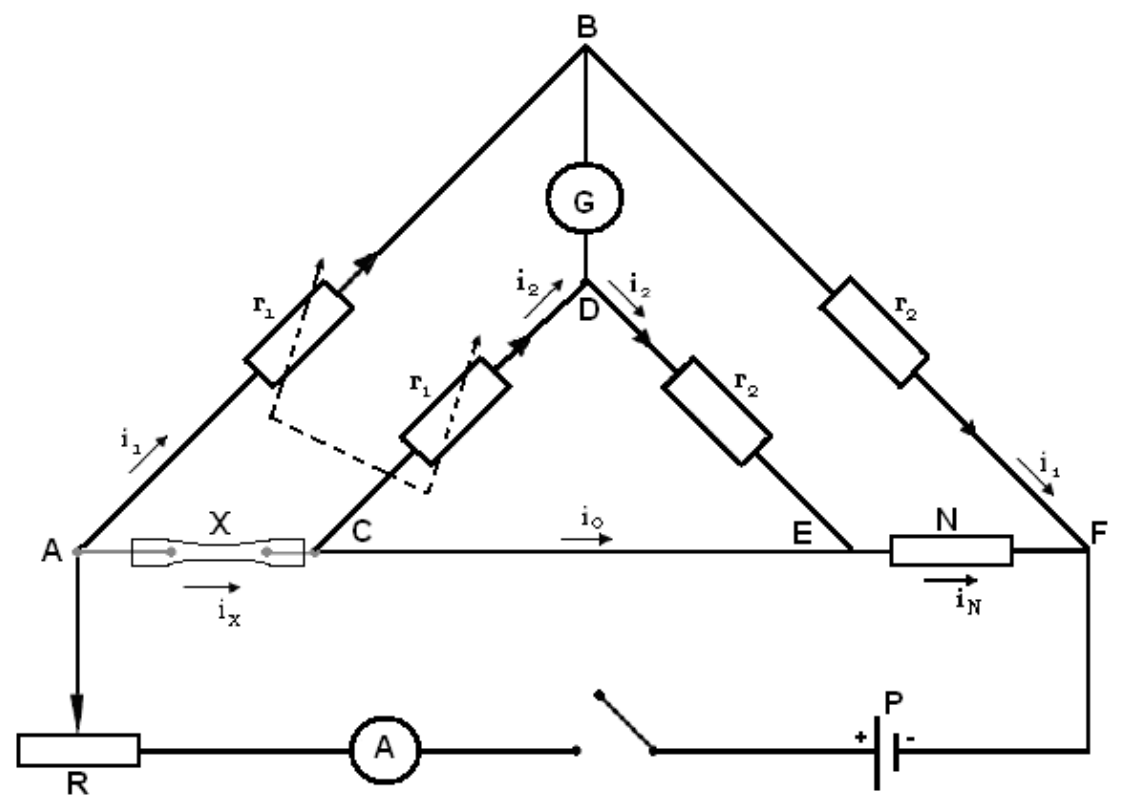

Figure 2: Wheatstone double bridge. 
specimen through a certain form, for example, by a heat treatment (Hörnqvist et al. [2]), to activate a "self-organization process", the specimen will return to a certain organized state and the damage created at the time of the cyclic stresses will be repaired. With this idea, the lifespan of the metal parts can be prolonged while applying a heat treatment, during or after fatigue. It becomes reasonable to believe that specific good heat treatments induce the formation of a certain more ordered type in the metal structure damaged by fatigue. The objective of our study is to seek and find the best annealing parameters which can increase the fatigue lifespan regarding the test-tubes (figure 1) out of aluminum 2024 partially damaged. The parameters concerned are: the temperature, the maintaining time in the furnace and the speed of cooling. The follow-up of fatigue damage and that of regeneration are dealt with by the use of a variation of the electrical resistivity ( $\mathrm{Li}$ et al. [3]). This physical characteristic is determined by the Wheatstone double bridge (Arkhanguelski et al. [4]), as shown in figure 2.

\section{Device of damage evolution and heat treatment}

A 2024 aluminium alloy is used as the test material in annealing of recrystallization state. Its chemical composition and mechanical characteristics are in the following tables.

Table 1: Chemical composition.

\begin{tabular}{|c|c|c|c|c|c|c|}
\hline Element & $\mathrm{Al}$ & $\mathrm{Si}$ & $\mathrm{Mg}$ & $\mathrm{Cu}$ & $\mathrm{Mn}$ & $\mathrm{Fe}$ \\
\hline $\mathbf{2 0 2 4}$ & Balance & $0.3 \%$ & $1.4 \%$ & $4.2 \%$ & $0.5 \%$ & $0.2 \%$ \\
\hline
\end{tabular}

Table 2: $\quad$ Mechanical characteristics of test material.

\begin{tabular}{|c|c|}
\hline Tensile strength $\left(\mathrm{R}_{\mathrm{m}}\right)$ & $350 \mathrm{MPa}$ \\
\hline Conventional limit of elasticity $\left(\mathrm{R}_{0.2 \%}\right)$ & $210 \mathrm{MPa}$ \\
\hline Lengthening percent $(\mathrm{A} \%)$ & $15 \%$ \\
\hline Modulus of elasticity $(\mathrm{E})$ & $78 \mathrm{GPa}$ \\
\hline Poisson's ratio $(\mathrm{v})$ & 0.31 \\
\hline
\end{tabular}

The specimens were damaged by sinusoidal cyclic stress between $260 \mathrm{MPa}$ and $300 \mathrm{MPa}$ with a solicitation frequency of $20 \mathrm{~Hz}$. The first batch is made up of 26 specimens cycled until 5000 cycles to create a quantity of fatigue damage, which we would like to suppress by using heat treatment [5]. But first, we have to find the best parameters of that heat treatment.

We know that the electric resistivity is a powerful method, which determines the micro cavities and defects in the microstructure of material $[6,7]$. In the present work, we would like to find the lowest value of resistivity when we change the parameters of heat treatment. 


\subsection{Effect of maintaining temperature}

We have used eight (08) specimens in different levels of temperature. The following figure shows the variation of electrical resistivity according to the variation of maintaining temperature.

From this figure, we deduce that $520^{\circ} \mathrm{C}$ will be retained for maintaining temperature at the time of regeneration of the initial properties.

\subsection{Effect of maintaining time}

The same tests as the precedents were done on twelve (12) specimens to determine the optimal maintaining time of heat treatment and the results are shown in the figure 4.

We deduce that the optimal time of heat treatment is 135 minutes.

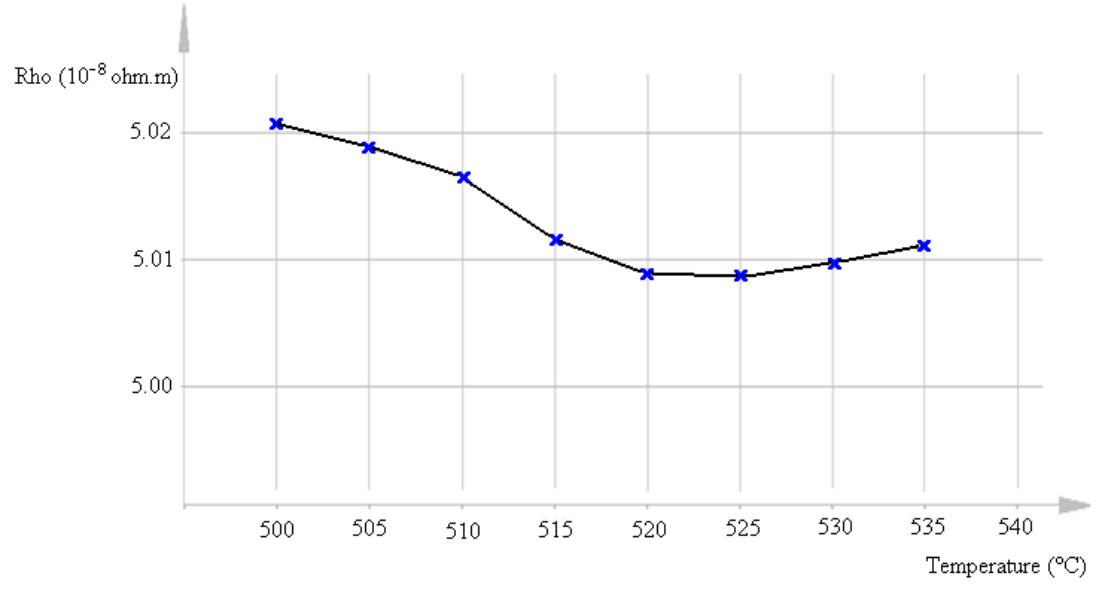

Figure 3: Evolution of electrical resistivity according to variation of maintaining temperature.

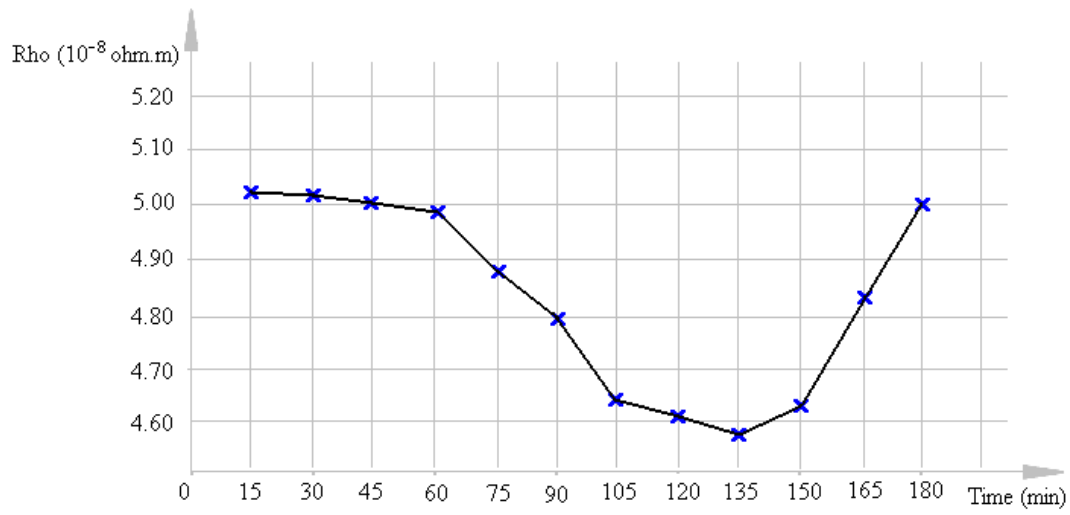

Figure 4: Evolution of electrical resistivity according to variation of maintaining time. 


\subsection{Effect of the cooling speed}

In these tests, we have to find the optimal cooling speed which will gives the lowest electrical resistivity. The results obtained are given in the figure 5.

We choose $0.5^{\circ} \mathrm{C} / \mathrm{min}$ as the optimal cooling speed to regenerate the initial properties.

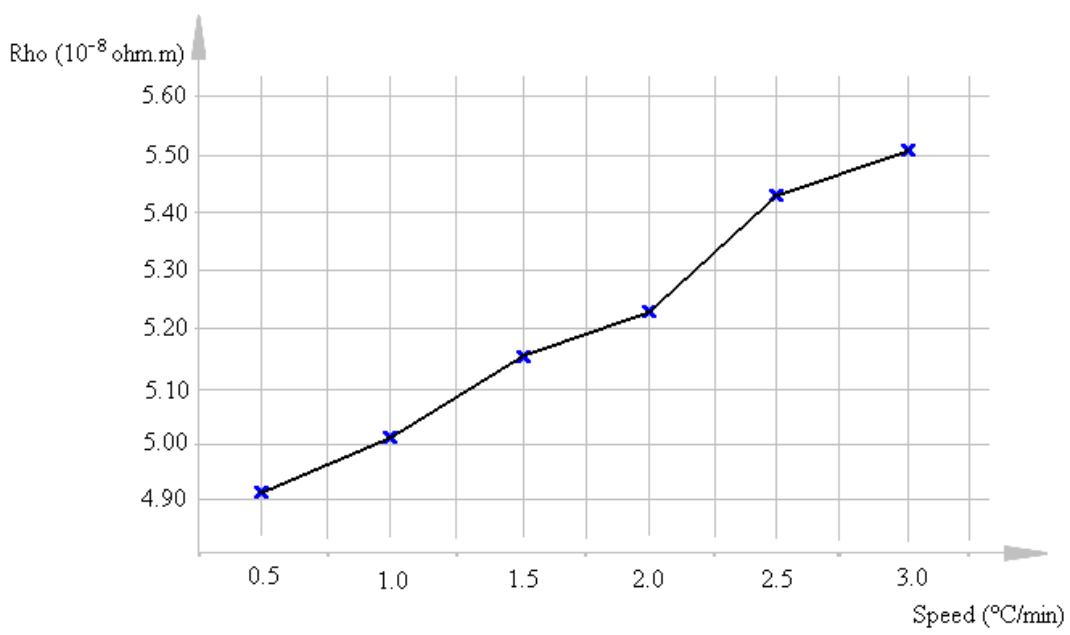

Figure 5: Evolution of electrical resistivity according to the cooling speed variation.

\section{Effect of heat treatment on fatigue life}

The results above indicate that the parameters of heat treatment regeneration should be properly selected to obtain the lowest value of electrical resistivity. As a conclusion, we select the following heat treatment: a heating temperature of up to $520^{\circ} \mathrm{C}$, maintaining this temperature for about 135 minutes, followed by a cooling under speed of $05^{\circ} \mathrm{C} / \mathrm{min}$.

As a basis of comparison, the original specimen fatigue life under the same cyclic stress conditions was determined experimentally. It follows a normal distribution: the average fatigue life is about 46000 cycles and the standard deviation is 0.185 .

We have six (06) batches, each one contain twelve virgin specimens. To generate a quantity of fatigue damage in our specimens, we will cycle all the specimens in the same conditions for different levels, in term of fatigue life, as shown in table 3.

After having generated the fatigue damage, we apply the predicted heat treatment. 
Finally, we continue again the cycling loading in the same conditions with the first step of creating fatigue damage until rupture, to compare the new obtained fatigue life with the original one.

Table 3: Levels of fatigue life in terms of damage for all the batches.

\begin{tabular}{|c|c|c|}
\hline $\mathrm{N}^{\circ}$ of batch & Level of fatigue damage & Proportion/fatigue life \\
\hline $\mathbf{0 1}$ & 5000 cycles & $10 \%$ \\
\hline $\mathbf{0 2}$ & 10000 cycles & $21 \%$ \\
\hline $\mathbf{0 3}$ & 15000 cycles & $32 \%$ \\
\hline $\mathbf{0 4}$ & 20000 cycles & $43 \%$ \\
\hline $\mathbf{0 5}$ & 25000 cycles & $54 \%$ \\
\hline $\mathbf{0 6}$ & 30000 cycles & $65 \%$ \\
\hline
\end{tabular}

We recapitulate all the results obtained in the following table.

The results listed in table 4 , indicate that the chosen heat treatment can significantly increase the fatigue life of our specimens. This increase has reached a value of $26 \%$ of the initial fatigue life in the first level.

Table 4: $\quad$ The average obtained fatigue life and the number of cycles gained after heat treatment.

\begin{tabular}{|c|c|c|c|c|}
\hline $\begin{array}{c}\mathrm{N}^{\circ} \text { of } \\
\text { batch }\end{array}$ & Initial cycles & Average fatigue life & Cycles gained & $\%$ of gain \\
\hline 01 & 5000 & 58000 & +12000 & $26 \%$ \\
\hline 02 & 10000 & 54000 & +8000 & $17 \%$ \\
\hline 03 & 15000 & 51000 & +5000 & $10 \%$ \\
\hline 04 & 20000 & 48000 & +2000 & $04 \%$ \\
\hline 05 & 25000 & 46000 & 000 & $00 \%$ \\
\hline 06 & 30000 & 46000 & 000 & $00 \%$ \\
\hline
\end{tabular}

\section{Effect of initial fatigue damage}

To show more of the results provided in table 4, we translate them into a graph shown in the following figure.

From the precedent graph, it is noticed that the initial fatigue damage has a great influence on the effect of the regeneration by heat treatment. If the initial fatigue damage is greater than a certain critical value (corresponding in this case to a fatigue duration of 25000 cycles), the regeneration is close to zero. The possible reason behind this is that the micro-crack appears and the heat treatment cannot repair damage of such a type. Microscopic clarification of this phenomenon needs further studying. 


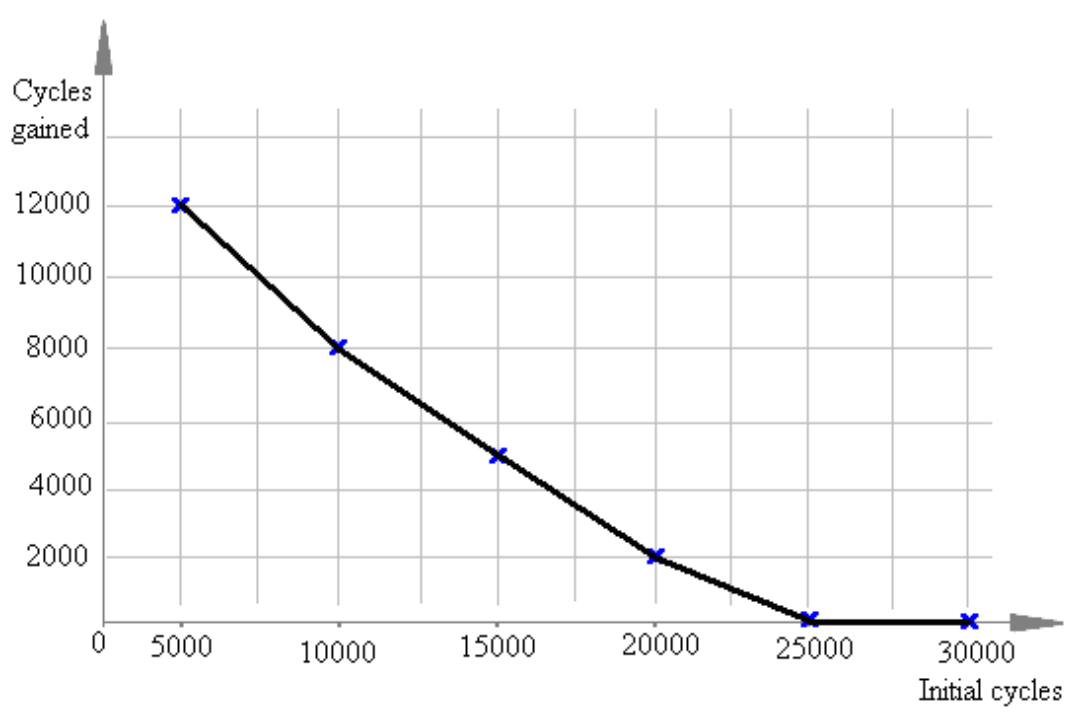

Figure 6: Cycles gained after heat treatment of all the specimens.

\section{Conclusion}

This contribution to regenerate the initial properties of the aluminium alloys after fatigue damage is based on the use of classical heat treatments to decrease the micro cavities created by this damage. The obtained results show that this regeneration is possible with appropriate treatment parameters if a certain threshold of damage is not reached. For the case considered in this work, we can say that:

- The damage-repairing effect of heat treatment increases with decrease of the initial damage.

- If the initial damage is greater than a certain critical value, the heat treatment is of no damage-repairing effect.

Finally, this process can be envisaged to increase the fatigue life of components when they are submitted to fatigue loading.

\section{References}

[1] Lü, B.T., Qiao, S.R. \& Sun, X.Y., Exploration on repairing fatigue damage of steel specimens with magnetic treatment, Pergamon: Scripta Materialia, Vol. 40, $\mathrm{N}^{\circ}$ 7; pp 767 771, 1999.

[2] Hörnqvist, M. \& Karlsson, B., Influence of heat treatment on the cyclic deformation properties of aluminium AA7030, Elsevier: Materials science \& engineering, pp 11, 2007. 
[3] Li, J., Qiao, S.R., Han, D. \& Li, M., Damage behaviors of TiAl alloy under thermal fatigue and thermal cycling with dead-load, Elsevier: Materials science \& engineering, pp 106 112, 2007.

[4] Arkhanguelski, S., Iouriev, V. \& Kliouchnik, I., physique of metal, University of Annaba, Algeria, 1984.

[5] Lebert, A.A., Etude expérimentale et prévision des mécanismes de rupture des toles et des joints soudés bout à bout en alliage d'aluminium 6065, Ecole des Mines de Paris, 2005.

[6] Mokdad, A., Contribution à l'étude de la fissuration des alliages d'aluminium utilisés en aéronautique, Ecole Militaire Polytechnique, Alger, 2008.

[7] Lemaître, J. \& Desmorat, R., Engineering Damage Mechanics (chapter 1), topics in damage, Springer-Verlag Berlin Heidelberg pp 01 06, 2005. 